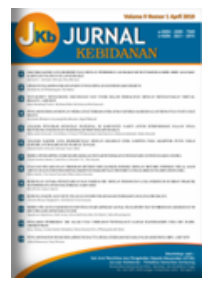

Volume 9 Nomor 2 (2019) 148-152

JURNAL KEBIDANAN

p-ISSN: 2089-7669; e-ISSN: 2621-2870

http://dx.doi.org/10.31983/jkb.v9i2.5237

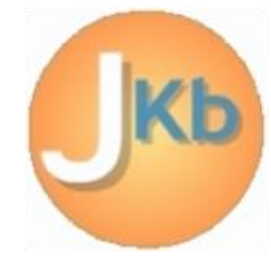

\title{
Influence of Physical and Psychological of Pregnant Women Toward Health Status of Mother and Baby
}

\author{
Alfiah Rahmawati ${ }^{1}$ Rr Catur Leny Wulandari ${ }^{2}$ \\ ${ }^{1,2}$ Universitas Islam Sultan Agung, Indonesia \\ Corresponding author: Alfiah Rahmawati \\ Email: alfiahrahmawati@ unissula.ac.id
}

Received: September 6th 2019; Revised: October 16 th 2019; Accepted: October 23th 2019

\begin{abstract}
Pregnancy is a natural event for women, a woman will experience changes in him both physically and psychologically. The two problems we face very often are the field of psychology of pregnant women is the feeling of fear and rejection of pregnancy. Physically there will be an enlargement of the abdomen, felt the movement / emergence of hyperpigmentation, the release of colostrum and anxiety. This feeling of fear and anxiety will arise in primiparous and multiparous pregnant women who are having a pregnancy. The purpose of this study was to determine the effect of physical and psychological readiness of third trimester pregnant women on the welfare of the mother and fetus. This study was an observational analytic study using a cross-sectional study design. Independent variables are age, education, marital status, parity. The dependent variable is the incidence of pre-eclampsia. Accidental sampling technique. This research was conducted in Rusunawa Kaligawe Semarang. Bivariate data analysis uses chi square test. The results showed that physical and psychological readiness variables were not related to maternal well-being with a $\mathrm{p}$ value of 0.369 ( $\mathrm{p}$ value $>0.05$ ). Variable physical and psychological readiness associated with fetal well-being with a $\mathrm{p}$ value of 0.018 ( $\mathrm{p}$ value $<0.05$ ). The conclusion is a statistically significant positive relationship between physical and psychological readiness of pregnant women and fetal well-being in Rusunawa Kaligawe Semarang City and there is no positive and statistically significant relationship between physical and psychological readiness of pregnant women towards maternal welfare.
\end{abstract}

Keyword: physical and psychological of pregnant women; health status of mother and baby

\section{Pendahuluan}

Kehamilan adalah serangkaian peristiwa yang diawali dengan konsepsi dan akan berkembang sampai menjadi fetus yang aterm dan diakhiri dengan proses persalinan [1]. Kehamilan adalah peristiwa kodrati bagi perempuan, seorang perempuan akan mengalami perubahan dalam dirinya baik fisik maupun psikologis. Dua persoalan yang amat sering kita hadapi adalah bidang ilmu jiwa wanita hamil adalah perasaan takut dan penolakan terhadap kehamilan. Secara fisik akan terjadi pembesaran perut, terasa adanya pergerakan/timbulnya hiperpigmentasi, keluarnya kolostrum dan sebagainya, atau kegelisahan yang dialami ibu hamil karena ibu hamil telah mendengar cerita-cerita tentang kehamilan dan persalinan dari orang-orang sekitar. Perasaan takut dan cemas ini akan timbul pada ibu hamil primipara dan multipara yang mengalami kehamilan. Namur keluarga, sering tidak memahami bahwa setiap kehamilan memiliki risiko [2]. 
Setiap saat kehamilan dapat berkembang menjadi atau mengalami penyulit/komplikasi. Berdasarkan hal tersebut diperlukan pemantauan kesehatan ibu hamil. Pemantauan ini meliputi pemeriksaan Antenatal (Ante Natal Cara/ANC). Pemeriksaan ini meliputi perubahan fisik normal yang dialami ibu serta tumbuh kembang janin, mendeteksi dan menatalaksana setiap kondisi yang tidak normal. Menurut dr. Nora L. Sondakh MA (2006) ada beberapa hal pemeriksaan ibu hamil secara keseluruhan. Pertama, memantau kemajuan kehamilan untuk memastikan kesehatan ibu dan tumbuh kembang janin. Kedua, meningkatkan dan mempertahankan kesehatan fisik, mental, dan social ibu. Ketiga, mengenali dan mengurangi secara dini adanya penyukit atau komplikasi yang mungkin terjadi selama hamil, termasuk riwayat penyakit secara umum. Keempat. Mempersiapkan persalinan cukup bulan dan persalinan yang aman dengan trauma seminimal mungkin. Kelima, mempersiapkan ibu agar mass nifas berjalan dengan normal dan mempersiapkan ibu agar dapat memberikan Air Susu Ibu (ASI) secara ekslusif Keenam, mempersiapkan peran ibu dan keluarga dalam menerima kelahiran janin agar dapat tumbuh kembang secara normal. Ketujuh, mengurangi bayi lahir prematur, kelahiran mati dan kematian neonatal, sedangkan yang terakhir mempersiapkan kesehatan yang optimal.

Selama proses itu berlangsung terjadi perubahan secara fisik maupun psikologi yang akan dialami oleh seorang ibu. Perubahan tersebut dapat menimbulkan ketidaknyamanan terutama di trimester III seperti dispnea, insomnia, gingivitis dan epulsi, sering buang air kecil, tekanan dan ketidaknyamanan pada perineum, nyeri punggung, konstipasi, varises, mudah lelah, kontraksi Braxton hicks, kram kaki, edema pergelangan kaki, dan perubahan mood, serta peningkatan kecemasan [3]. Sebagian besar ibu yang sedang hamil sering mengalami ketakutan dan kecemasan menghadapi proses persalinan karena rasa sakit akibat persalinan. Hal tersebut dapat menimbulkan ketegangan jiwa dan fisik yang akan mengakibatkan otot dan persendian menjadi kaku yang tidak wajar. Stres atau kecemasan terkait dengan berbagai hasil kehamilan, rasa sakit, dan keluhan somatik lain yang sering terjadi dengan gangguan mood pada ibu hamil [4].

Gangguan psikologis yang terjadi dapat berpengaruh buruk terhadap perkembangan janin dan mengakibatkan stres berkepanjangan yang dapat berefek pada terhambatnya perkembangan janin termasuk gangguan emosi setelah kelahiran, apabila tidak ditangani dengan baik meski dengan asupan nutrisi yang baik. Gangguan psikologis dapat meningkatkan risiko terjadinya komplikasi dalam persalinan, sehingga diperlukan pencegahan dengan beberapa metode untuk meringankan dan mempersiapkan ibu dalam menjaga kehamilan dan proses persalinan [5]. Ibu hamil harus mendapat asuhan kehamilan agar dapat beradaptasi dengan perubahan yang terjadi baik fisik maupun psikologinya. Tujuan asuhan selama masa kehamilan untuk mempersiapkan persalinan yang fisiologis dengan tujuan ibu dan janin yang akan dilahirkan dalam keadaan sehat [6].

Kematian ibu dapat dicegah hingga 22\% yaitu melalui antenatal care yang teratur, mendeteksi dini adanya komplikasi dalam kehamilan, hidup sehat dengan pemenuhan gizi yang seimbang, pelaksanaan inisiasi menyusui dini dalam persalinan, serta pelaksanaan senam hamil secara teratur. Sangat penting bagi wanita untuk mempertahankan atau memperbaiki kondisi fisiknya bila ia ingin kehamilan yang terbaikdan untuk menghadapi stress yang dialami tubuhnya karena perkembangan janin.

Penyebab kematian ibu tersebut karena kehamilan atau persalinan yang disebabkan oleh aspek medis, sosial, budaya dan agama. Salah satu aspek medis tersebut yaitu persalinan dengan komplikasi. Komplikasi dalam kehamilan seperti kehamilan ektopik, hiperemesis gravidarum, abortus, eklamsia, plasenta previa yang sangat mengancam nyawa ibu hamil. Dalam mengatasi penyebab masalah tersebut diperlukan pendekatan yang berkualitas yang dimulai sejak perencanaan kehamilan dan selama masa kehamilan.

Bidan diakui sebagai tenaga profesional yang bertanggung jawab dan akuntabel, yang bekerja sebagai mitra perempuan untuk memberikan dukungan, asuhan dan nasehat selama masa hamil. Asuhan yang mencakup upaya pencegahan, promosi persalinan normal, deteksi komplikasi pada ibu dan anak, dan akses bantuan medis atau bantuan lain yang sesuai, serta melaksanakan tindakan kegawat-daruratan. Bidan mempunyai tugas penting dalam konseling dan pendidikan kesehatan, tidak hanya kepada perempuan, tetapi juga kepada keluarga dan masyarakat. Salah satu kegiatannya adalah mencakup pendidikan antenatal.

Masalah yang dapat ditegakkan pada penelitian ini adalah bagaimana pengaruh kesiapan fisik dan psikologis ibu hamil terhadap status kesejahteraan ibu dan janin?. Tujuam penelitian adalah mengidentifikasi pengaruh kesiapan fisik 
dan psikologis ibu hamil terhadap status kesejahteraan ibu dan janin ibu hamil trimester III.

\section{Metode Penelitian}

Jenis dan rancangan penelitian yang digunakan dalam penelitian ini adalah analitik observasional, sedang metode pendekatan yang digunakan adalah crossectional. Masalah yang dikaji pada penelitian ini adalah ilmu kebidanan terutama asuhan kehamilan dilaksanakan di Rusunawa Kaligawe. Variabel independennya kesiapan fisik dan psikologis ibu hamil. Variabel dependennya adalah status kesejahteraan ibu dan janin.

Populasi pada penelitian ini adalah seluruh ibu hamil trimester III di Rusunawa Kaligawe. Sampel adalah sebagian dari jumlah dan karakteristik yang dimiliki oleh populasi tersebut. Sampel pada penelitian ini adalah semua ibu hamil trimester III yang diperiksa di Rusunawa Kaligawe pada bulan Juli-Agustus 2018 sebanyak 70 ibu hamil. Teknik sampling yang digunakan adalah Total Sampling.

Setelah seluruh data yang dikumpulkan, disajikan dalam bentuk tabel, kemudian diolah dengan menggunakan perhitungan chi square untuk mengetahui pengaruh kesiapan fisik dan psikologis terhadap status kesejahteraan ibu dan janin. Uji statistik yang digunakan dalam analisis multivariat adalah Regresi Logistik.

Penelitian ini sudah mendapatkan persetujuan Ethical Clearance dari Komisi Bioetika Penelitian Kedokteran/ Kesehatan Fakultas Kedokteran Universitas Islam Sultan Agung Semarang dengan no. 646/ X/ 2019/ Komisi Bioetik.

\section{Hasil dan Pembahasan}

\section{Tabel 1}

Distribusi frekuensi responden berdasarkan terjadinya kesiapan fisik dan psikologis, kesejahteraan ibu, kesejahteraan janin, umur, paritas, gravida, pendidikan, dan pekerjaan ibu

\begin{tabular}{lcc}
\hline \multicolumn{1}{c}{ Karakteristik } & Jumlah & Persentase \\
\hline Kesiapan Fisik Psikologis & & \\
\hline Siap & 30 & 42.90 \\
\hline Kurang & 40 & 57.10 \\
\hline Kesejahteraan Ibu & & \\
\hline Baik & 37 & 52.90 \\
\hline$\quad$ Kurang & 33 & 47.10 \\
\hline Kesejahteraan Janin & & \\
\hline
\end{tabular}

\begin{tabular}{lcc}
\hline Baik & 52 & 74.30 \\
\hline Kurang & 18 & 25.70 \\
\hline Usia & & \\
\hline$\quad$ 20 atau >35 tahun & 1 & 1.4 \\
\hline 20-35 tahun & 69 & 98.6 \\
\hline Gravida & & \\
\hline Primigravida & 33 & 47.10 \\
\hline$\quad$ Multigravida & 37 & 52.90 \\
\hline Pendidikan & & \\
\hline Rendah & 46 & 65.70 \\
\hline Tinggi & 24 & 34.30 \\
\hline Pekerjaan & & \\
\hline Bekerja & 21 & 30.00 \\
\hline Tidak & 49 & 70.00 \\
\hline
\end{tabular}

Berdasarkan tabel 1 diketahui bahwa ibu hamil yang siap fisik dan psikologis adalah sebanyak 30 responden $(42,90 \%)$ sedangkan yang kurang siap adalah sebanyak 40 responden $(57,10 \%)$. Kesejahteraan ibu yang baik adalah sebanyak 37 responden $(52,90 \%)$ sedangkan yang kurang baik adalah sebanyak 33 responden $(47,10 \%)$. Sedangkan usia yang $<20$ tahun dan $>35$ tahun adalah sebanyak 1 responden $(1,4 \%)$ dan yang 20-35 tahun adalah sebanyak 69 responden $(98,6 \%)$. Berdasarkan gravida yang primigravida adalah sebanyak 33 responden $(47,10 \%)$ sedangkan yang multipara adalah sebanyak 37 responden $(52,90 \%)$. Pada tingkat pendidikan didapatkan pendidikan yang rendah adalah sebanyak 46 responden $(65,70 \%)$ sedangkan yang tinggi adalah sebanyak 24 responden $(34,30 \%)$. Sedangkan pada pekerjaan yang bekerja adalah sebanyak 21 responden (30\%) sedangkan yang tidak bekerja adalah sebanyak 49 responden (70\%)

Analisis bivariat dilakukan untuk mengetahui keterkaitan antara variabel bebas dengan variabel terikat. Dalam hal ini untuk mengetahui hubungan kesiapan fisik dan psikologis terhadap kesejahteraan ibu dan janin dengan menggunakan analisis korelasi Chi Square dengan sebagai berikut:

\section{Tabel 2}

Hubungan Kesiapan Fisik dan Psikologis dengan Kesejahteraan Ibu

\begin{tabular}{lccccc}
\hline \multirow{2}{*}{$\begin{array}{c}\text { Kesiapan } \\
\text { Fisik \& }\end{array}$} & \multicolumn{4}{c}{ Kesejahteraan Ibu } & \multirow{2}{*}{ Nilai } \\
\cline { 2 - 4 } \multicolumn{1}{c}{ Psikologis } & $\mathbf{N}$ & $\mathbf{\%}$ & $\mathbf{N}$ & $\mathbf{\%}$ & p \\
\cline { 2 - 5 } & $\mathbf{N}$ & \\
\hline Kurang & 23 & 57,5 & 17 & 42,5 & \\
Siap & 14 & 46,7 & 16 & 53,3 & 0,369 \\
Total & 37 & 52,9 & 33 & 47,1 & \\
\hline
\end{tabular}


Keterangan : Uji Chi Square

Berdasarkan tabel 2 menunjukkan variabel kesiapan fisik dan psikologis tidak berhubungan dengan kesejahteraan ibu dengan nilai $\mathrm{p}$ value 0,369 (nilai $\mathrm{p}>0.05$ ).

\section{Tabel 3}

Hubungan Kesiapan Fisik dan Psikologis dengan Kesejahteraan Janin

\begin{tabular}{|c|c|c|c|c|c|}
\hline \multirow{3}{*}{$\begin{array}{l}\text { Kesiapan } \\
\text { Fisik \& } \\
\text { Psikologis }\end{array}$} & \multicolumn{4}{|c|}{ Kesejahteraan Ibu } & \multirow{3}{*}{$\begin{array}{c}\text { Nilai } \\
\text { p* }\end{array}$} \\
\hline & \multicolumn{2}{|c|}{ Baik } & \multicolumn{2}{|c|}{ Kurang } & \\
\hline & $\mathbf{N}$ & $\%$ & $\mathbf{N}$ & $\%$ & \\
\hline Kura & 34 & 85,0 & & 15,0 & \\
\hline Siap & 18 & 60,0 & 12 & 40,0 & 0,0 \\
\hline Total & 52 & 74,3 & 18 & 25,7 & \\
\hline
\end{tabular}

Keterangan : Uji Chi Square

Berdasarkan tabel 3 menunjukkan variabel kesiapan fisik dan psikologis berhubungan dengan kesejahteraan janin dengan $\mathrm{p}$ value 0,018 (nilai $\mathrm{p}$ $<0.05)$.

\section{Hubungan Kesiapan Fisik dan Psikologis dengan Kesejahteraan Ibu}

Berdasarkan Tabel 2 hubungan kesiapan fisik dan psikologis dengan kesejahteraan ibu dengan $p$ Value 0,369 yang artinya $>0,05$ sehingga tidak ada hubungan kesiapan fisik dan psikologis dengan kesejahteraan ibu.

Setiap saat kehamilan dapat berkembang menjadi atau mengalami penyulit/komplikasi. Berdasarkan hal tersebut diperlukan pemantauan kesehatan ibu hamil. Pemantauan ini meliputi pemeriksaan Antenatal (Ante Natal Cara/ANC). Pemeriksaan ini meliputi perubahan fisik normal yang dialami ibu serta tumbuh kembang janin, mendeteksi dan menatalaksana setiap kondisi yang tidak normal. Beberapa hal pemeriksaan ibu hamil secara keseluruhan. Pertama, memantau kemajuan kehamilan untuk memastikan kesehatan ibu dan tumbuh kembang janin. Kedua, meningkatkan dan mempertahankan kesehatan fisik, mental, dan social ibu. Ketiga, mengenali dan mengurangi secara dini adanya penyukit atau komplikasi yang mungkin terjadi selama hamil, termasuk riwayat penyakit secara umum. Keempat. Mempersiapkan persalinan cukup bulan dan persalinan yang aman dengan trauma seminimal mungkin. Kelima, mempersiapkan ibu agar mass nifas berjalan dengan normal dan mempersiapkan ibu agar dapat memberikan Air Susu Ibu (ASI) secara ekslusif Keenam, mempersiapkan peran ibu dan keluarga dalam menerima kelahiran janin agar dapat tumbuh kembang secara normal. Ketujuh, mengurangi bayi lahir prematur, kelahiran mati dan kematian neonatal, sedangkan yang terakhir mempersiapkan kesehatan yang optimal [7].

Selama proses itu berlangsung terjadi perubahan secara fisik maupun psikologi yang akan dialami oleh seorang ibu. Perubahan tersebut dapat menimbulkan ketidaknyamanan terutama di trimester III seperti dispnea, insomnia, gingivitis dan epulsi, sering buang air kecil, tekanan dan ketidaknyamanan pada perineum, nyeri punggung, konstipasi, varises, mudah lelah, kontraksi Braxton hicks, kram kaki, edema pergelangan kaki, dan perubahan mood, serta peningkatan kecemasan [8]. Sebagian besar ibu yang sedang hamil sering mengalami ketakutan dan kecemasan menghadapi proses persalinan karena rasa sakit akibat persalinan. Hal tersebut dapat menimbulkan ketegangan jiwa dan fisik yang akan mengakibatkan otot dan persendian menjadi kaku yang tidak wajar. Stres atau kecemasan terkait dengan berbagai hasil kehamilan, rasa sakit, dan keluhan somatik lain yang sering terjadi dengan gangguan mood pada ibu hamil [4][3].

\section{Hubungan Kesiapan Fisik dan Psikologis dengan Kesejahteraan Janin}

Berdasarkan tabel 3 menunjukkan variabel kesiapan fisik dan psikologis berhubungan dengan kesejahteraan janin (nilai $\mathrm{p}<0.05$ ).

Keadaan kesejahteraan janin dipengaruhi oleh berbagai faktor, diantaranya faktor keturunan dan kondisi kesehatan orang tuannya. Demgan demikian untuk mengupayakan mendapat keturunan yang sehat, sebaiknya orang tua dapat menyiapkan diri secara fisik maupun psikologik jauh sebelum kehamilan dimulai. Pentingnya kesehatan fisik seperti gizi yang cukup, menghindari pemakaianobat-obatan, merokok, alkohol dan lain-lain begitu pula pentingnya kesiapan psikologik.Terlebih bagi wanita yang mempunyai kecenderungan tejadinya masalah perinatal, seperti wanita dengan diabetes mellitus, yang mana sering diikuti terjadinyakelainan bawaan, atau hipertensi yang sering diikuti insuffiesiensi plasenta dan IUGR (Intra Uterine Growth Retardation) atau terhambatnya pertumbuhan janin dalam rahim,sangat diperlukan dukungan berupa 
perawatan dan konseling dalam upaya menekanresiko seminimal mungkin.

Gangguan psikologis yang terjadi dapat berpengaruh buruk terhadap perkembangan janin dan mengakibatkan stres berkepanjangan yang dapat berefek pada terhambatnya perkembangan janin termasuk gangguan emosi setelah kelahiran, apabila tidak ditangani dengan baik meski dengan asupan nutrisi yang baik. Gangguan psikologis dapat meningkatkan risiko terjadinya komplikasi dalam persalinan, sehingga diperlukan pencegahan dengan beberapa metode untuk meringankan dan mempersiapkan ibu dalam menjaga kehamilan dan proses persalinan [7]. Ibu hamil harus mendapat asuhan kehamilan agar dapat beradaptasi dengan perubahan yang terjadi baik fisik maupun psikologinya. Tujuan asuhan selama masa kehamilan untuk mempersiapkan persalinan yang fisiologis dengan tujuan ibu dan janin yang akan dilahirkan dalam keadaan sehat [6].

Kematian ibu dapat dicegah hingga $22 \%$ yaitu melalui antenatal care yang teratur, mendeteksi dini adanya komplikasi dalam kehamilan, hidup sehat dengan pemenuhan gizi yang seimbang, pelaksanaan inisiasi menyusui dini dalam persalinan, serta pelaksanaan senam hamil secara teratur. Sangat penting bagi wanita untuk mempertahankan atau memperbaiki kondisi fisiknya bila ia ingin kehamilan yang terbaik dan untuk menghadapi stress yang dialami tubuhnya karena perkembangan janin.

Kondisi fisik ibu hamil dengan usia lebih dari 35 tahun akan sangat menentukan proses kelahirannya. Hal ini turut memengaruhi kondisi janin. Pada proses pembuahan, kualitas sel telur perempuan pada usia ini telah menurun jika dibandingkan dengan sel telur pada perempuan dengan usia reproduksi sehat (25-30 tahun). Jika pada proses pembuahan, ibu mengalami gangguan sehingga menyebabkan terjadinya gangguan perkemihan dan perkembangan buah kehamilan, maka kemungkinan akan menyebabkan terjadinya Inta Uterine Growth Retardation (IUGR) yang berakibat bayi berat lahir rendah (BBLR). Kontraksi uterus juga sangat dipengaruhi oleh kondisi fisik ibu. Jika ibu mengalami penurunan kondisi, terlebih pada primitua (hamil pertama dengan usia lebih dari 40 tahun), keadaan ini harus benar-benar diwaspadai.

Kemampuan fisik adalah kemampuan memfungsikan organ-organ tubuh dalam melakukan aktivitas fisik. Kemampuan fisik sangat penting untuk mendukung mengembangkan aktifitas psikomotor [7]. Gerakan yang terampil dapat dilakukan apabila kemampuan fisiknya memadai. Menurut Kondisi fisik adalah satu kesatuan utuh dari komponen-komponen yang tidak dapat dipisahkan begitu saja, baik peningkatan maupun pemeliharaan [9]. Artinya bahwa di dalam usaha peningkatan kondisi fisik maka seluruh komponen tersebut harus berkembang.

\section{Simpulan}

Tidak terdapat hubungan kesiapan fisik dan psikologis ibu hamil terhadap kesejahteraan ibu. Terdapat hubungan kesiapan fisik dan psikologis terhadap kesejahteraan janin.

\section{Daftar Pustaka}

[1] Guyton A.C. and J.E. Hall., Buku Ajar Fisiologi Kedokteran. Edisi 9. Jakarta: EGC, 2007.

[2] Manuaba, Ilmu Kebidanan Penyakit Kandungan dan KB. Jakarta: EGC, 2010.

[3] M. Hariyanto, "Pengaruh Senam Yoga terhadap Tingkat Kecemasan Ibu Hamil Trimester III di Praktik Bidan Mandiri Kabupaten Boyolali,” 2015.

[4] P. Y. Wulandari, "Efektivitas Senam Hamil sebagai Pelayanan Prenatal dalam Menurunkan Kecemasan Menghadapi Persalinan Pertama," INSAN, vol. 8, no. 2, 2006.

[5] M. V. Thoma, R. La Marca, R. Brönnimann, L. Finkel, U. Ehlert, and U. M. Nater, "The Effect of Music on the Human Stress Response," PLoS One, vol. 8, no. 8, pp. 1-12, 2013.

[6] Depkes, "Rencana Pembangunan Jangka Panjang Bidang Kesehatan 2005-2025," Jakarta, 2009.

[7] E. Rusmita, "Pengaruh Senam Hamil Yoga selama Kehamilan terhadap Kesiapan Fisik dan Psikologis dalam Menghadapi Persalinan pada Ibu Hamil Trimester III di RSIA Limijati Bandung," Universitas Indonesia, 2011.

[8] I. Bobak, Lowdermilk, and Jensen, Buku Ajar Keperawatan Maternitas. Edisi 4. Jakarta: EGC, 2004.

[9] R. Nim, "Pengaruh kenyamanan lingkungan fisik ruang rawat inap kelas iii terhadap kepuasan pasien di rsui kustati surakarta skripsi," pp. 1-46, 2009. 